\title{
Comer, alimentar e nutrir: categorias analíticas instrumentais no campo da pesquisa científica
}

\author{
Eating, nourishment and nutrition: \\ instrumental analytic categories in the scientific research field
}

Maria Cláudia da Veiga Soares Carvalho ${ }^{1}$

$M$ adel Therezinha Luz ${ }^{2}$

Shirley DonizetePrado ${ }^{1}$

1 Programa de PósGraduação em Alimentação, Nutrição eSaúde, Núcleo de Estudos sobre Cultura e Alimentação, Departamento deNutrição Social, Instituto deNutrição, Universidade do Estado do Rio deJaneiro. Av. São Francisco Xavier, $524,12^{\circ}$ andar, bloco $\mathrm{E}$, sala 12.007, M aracanã. 20550900 Rio deJaneiro RJ. mariaclaudiaveigasoares@ yahoo.com.br

${ }^{2}$ Departamento de

Planejamento e

Administração em Saúde,

Instituto deM edicina Social, Universidade do Estado do Rio deJaneiro.
Abstract Eating, nourishment or nutrition circulate in our culture as synonyms and thus do not account for the changes that occur in nourishment, which intended or unintended, have a hybridization pattern that represents a change of rules and food preferences. This paper aims to take these common sense conceptions as analytic categoriesfor analyzing and interpreting research for the H umanities and $\mathrm{H}$ ealth Sciences in a the oretical perspective, through conceptualization. The food is associated with a natural function (biological), a concept in which nature is opposed to culture, and nourishment takes cultural meanings (symbolic), expressing the division of labor, wealth, and a historical and cultural creation through which one can study a society. One attributes to Nutrition a sense of rational action, derived from the constitution of this science in modernity, inserted in a historical process of scientific rationalization of eating and nourishing. We believe that through the practice of conceptualization in interdisciplinary research, which involves a shared space of knowledge, we can be less constrained by a unified theoretical model of learning and be freer to think about life issues. Key words Epistemology, Scientific field, Culture, Food, Nutrition
Resumo Comer, alimentar ou nutrir circulam na nossa cultura, aproximadamente, como sinônimos e desse modo não dão conta das transformações quevêm ocorrendo na alimentação, quedesejadas ou indesejadas contam com um hibridismo de padrões que representa uma mudança tanto de regras como de preferências alimentares. 0 objetivo do artigo é tornar essas concepções de senso comum categorias de análise e interpretação para pesquisas das Ciências H umanase da Saúde, numa perspectiva teórica, através da conceituação. N este espaço interdisciplinar da Nutrição e das Ciências Sociais, o alimento aparece associado a uma função natural (biológica), numa concepção em que natureza se contrapõe à cultura, e a comida assume sentidos e significados culturais (simbólicos). A alimentação expressa divisão do trabalho, da riqueza, é criação histórico-cultural através da qual se pode estudar uma soci edade. A tribui-se à Nutrição um sentido de ação racional, oriundo da constituição dessa ciência na modernidade, inserida num processo histórico deracionalização científica do comer edo alimentar-se. Consideramosque através da conceituação na prática interdisciplinar de pesquisa, que envolveum espaço compartiIhado de saberes, podemos ser menos limitados por um modelo teórico uniformizado de saber e mais livres para pensar questões sobre a vida.

Palavras-chave Epistemologia, Campo científico, Cultura, Alimentação, N utrição 
Introdução

No cotidiano da casa, da rua, do trabalho, o comer, o nutrir ou o alimentar são "palavras" que circulam na nossa cultura mais ou menos como sinônimos, com ligeiras variações de aplicação, no mais das vezes definidas por questões circunstanciais, ou práticas do senso comum que, quando colocadas sob a lente da ciência, podem ser esclarecedoras da realidade em que habitam, assumindo significados peculiares, construindo sentidos específicos nas ações sociais. Este trabaIho investe na operacionalidade dessas concepções, fazendo uma articulação entre a construção teórica ea pesquisa empírica, propondo uma transposição de concepções do senso comum para o meio científico, tornando-as instrumentos de análise e interpretação úteis para as pesquisas sobre práticas al imentares através de uma estratégia metodológica de conceituação.

N ossas discussões sobre "comer", "alimentar" e "nutrir", em foco neste texto, partiram das apresentações orais de Luz e de Prado no XX Congresso Brasileiro de Nutrição de 2008, abordagens situadas na interface do campo denominado Alimentação e Nutrição com as Ciências Humanas e Sociais ${ }^{1,2}$. Buscamos responder às questões sobre como essas concepções se constituem em nossa vida, levando-se em conta não somente uma perspectiva "nutricional", restrita à composição nutricional dos alimentos e seus efeitos metabólicos na fisiopatologia humana, mas uma perspectiva que seja capaz também de integrar os aspectos social e cultural pertinentes a essas concepções; perguntamos: o que significa cada uma delas em um mundo híbrido, com ritmo dinâmico e diversidade cultural como a contemporânea?

A abordagem teórica que propomos busca objetificar essas concepções espontâneas da realidade construindo categorias analíticas não somente para esclarecer seu caráter comunicativo no discurso na prática, mas também para refle tir sobre como elas organizam uma forma de pensamento contemporâneo. Não nos compete neste trabalho delimitar fronteiras disciplinares das Ciências Sociais e Humanas, mas, ao contrário, buscar uma liberdade, como defende Bourdieu $^{3}$, para expandi-las com a contrapartida de uma extrema vigilância das condições de utilização das técnicas, da sua adequação ao problema posto e às condi ções do seu emprego. Numa perspectiva socioantropológica, a estratégia metodológica deste trabalho se apoia numa ruptura entre senso comum e ciência ${ }^{4}$, que fundamenta 0 aprofundamento e a explicitação de concepções que, embora estejam natural izadas demodo pessoal na prática, em razão de valores individuais dominantes, expressam valores sociais e devem permanecer ao abrigo de uma relativização, o que demanda uma construção conceitual permanente. Então conceituar ${ }^{5}$, nesse sentido, é um método de definição da perspectiva de análise e de seleção de fundamentos, argumentos e teorias para sustentar a construção das novas categorias de análise. Categorias que são intelectualmente construídas para tornar seu uso na realidade cotidiana inteligível para a pesquisa científica, sem com isso se confundir com ela.

Pensar a "Alimentação" nesta interface não é somente uma questão de somar saberes, mas de fazer ciência e de pensar as relações sociais em seu contexto histórico e social ${ }^{6}$. U ma análise que parte deum conhecimento especializado em uma disciplina com rígidas fronteiras conceituais, inflexíveis, restringiria as possibilidades do pensar a espessura e a profundidade das questões da "Alimentação" em sua materialidade. A prática da pesquisa multi, inter e transdisciplinar vem sendo um desafio conceitual (epistemológico) e da ação (práxis) da Saúde Coletiva. Segundo Luz ${ }^{7}$, os objetos de investigação vêm se tornando cada vez mais com plexos, tanto no discurso quanto na prática: a produção discursiva tende a ser cooperativa entre os distintos saberes, que tomam um tema estratégico para a vida humana e social como proposta de investigação ( por exemplo, a violência, a Aids...; o que, a nosso ver, justifica a relevância e o interesse deste trabal ho.

M esmo a Epidemiologia, segundo Czeresnia8, convive com o desafio de se articular eseintegrar com as Ciências Sociais, entendendo queo corpo se apresenta dissociado nas diferentes perspectivas que o estudam. Segundo essa autora, as tentativas, tanto de quantificar as rel ações entre saúde e sociedade como as de isolar a dimensão de qualidade dentro das Ciências Sociais, são avessas à integração, pois qualidade e quantidade são duas faces inseparáveis dos fenômenos. A distinção que se faz entre pesquisa qualitativa e quantitativa representa apenas uma oposição constitutiva da divisão social do trabalho científico. Uma oposição a ser superada, pois segundo Bourdieu ${ }^{3}$, mesmo a oposição entre metodologia e teoria deveria ser ultrapassada, pois é somente em função de um corpo de hipóteses derivado de um conjunto de pressuposições teóricas que um dado empírico qualquer pode funcionar como prova ou, como dizem os anglo-saxônicos, como evidence. 
A integração disciplinar que sealmeja na prática acadêmica ainda não é realidade, por exemplo, nos cursos de graduação de N utrição no Brasil, embora haja disciplinas das Ciências Sociais Aplicadas nesta graduação no currículo básico. Um estudo de Canesqui e Garcia,10 mostra como as disciplinas Antropologia, Sociologia e Psicologia ainda passam rapidamente e sem compromisso ou consequência nos currículos de formação de nutricionistas. Na maior parte das vezes, essas disciplinas apresentam um conteúdo básico eteórico deCiências Sociais e H umanas que nem sempreé articulado à Nutrição, sem um mínimo de clareza acerca de seu papel na formação do profissional e sem maiores explicitações sobre 0 que se espera dessas disciplinas no campo da pesquisa científica e na prática profissional.

Construir recursos teóricos para uma análise interpretativa auxilia na compreensão da dimensão simbólica das práticas sociais, pois os atos da comunicação entre observador e observado são sempresocial esituacional mente determinados ${ }^{11}$. O conceito de campo, nos termos de Bourdieu ${ }^{3}$, é instrumental na construção e atualização de um jogo simbólico, quesedá na realidade, circunscrito a um espaço social, e que impõe regras que organizam a construção de concepções, que vai orientar a compreensão da realidade na prática da pesquisa. As regras de um campo como o da "Alimentação", longe deserem estáticas, se constituem com um "processo" dinâmico de construção e reconstrução, e apresentam tanto transformações como continuidades em suas etapas, seja a da produção, seja a do consumo ou a do trabaIho do homem na sociedade contemporânea. Segundo Arnai $z^{12}$, as transformações podem ser vistas na intensificação da produção agrícola, orientação de políticas de oferta e demanda de determinados alimentos, a concentração dos negócios em empresas multinacionais, a ampliação e especialização por meio de redes comerciais cada vez mais onipresentes e, definitivamente, a internacionalização da alimentação.

A compreensão desse processo dinâmico em nossa sociedade está ligada tanto à percepção da realidade objetiva quanto à elaboração de um discurso capaz de expressá-la. Quais as concepções, domínios e interesses presentes na constituição de campos científicos quando se tematiza o comer, a "Nutrição" e a "Alimentação"? Não é nossa pretensão, aqui, dar conta dessa questão que opera, para nós, como um norte nos nossos esforços acadêmicos - senão para buscar uma primeira aproximação teórica a essa complexa imensidão.

\section{O alimento ea comida}

Segundo Bourdieu ${ }^{13,14}$, não basta referir-se ao contexto social contentando-se em estabelecer uma relação direta entre o texto e o contexto; é preciso perceber as leis sociais que regem um determinado espaço social, um campo, quese constitui como um microcosmo, obedecendo a regras e interesses instituídos dentro dele mesmo, pois não se compreendenada senão se compreende o campo que o produz equel he confere sua pequena força. A biomedicina, em suas pesquisas, se apropria do "alimento", compreendendo-o como elemento da ordem da natureza associado a uma concepção de corpo orgânico funcional e objeto de modificações nesse corpo. As Ciências Sociais têm a "comida" como elemento da ordem da cultura ${ }^{15}$, associada a uma concepção de corpo social em que ela é expressão de uma forma de organização social.

$\mathrm{N}$ ão pretendemos nos aprofundar na contraposição que pode ser desenvolvida entre cultura e natureza, e de algum modo superar essa dualidade, entendendo esses conceitos como apenas algumas das partes da realidade complexa, que podem se articular ora concorrentes, ora sinérgicos na pesquisa científica. Comparar diferentes perspectivas, aqui, neste trabalho, segue 0 desafio epistemológico e da ação quefala Luz ${ }^{7}$ na busca pela multi, inter e transdisciplinaridadeno campo da Saúde.

Se por um lado, no campo das Ciências $\mathrm{Na}$ turais, o valor do "alimento" está, hegemonicamente, relacionado à sua composição química, qualidade sanitária, inocuidade, tecnologias de produção edistribuição e possi bilidades terapêuticas, por outro, no campo das Ciências Sociais, a "comida" ocupa um lugar de expressão da estrutura social de um grupo, de sua organização. Cada qual elabora o seu próprio conjunto articulado de questões na definição de seu objeto científico, que obedece a um conjunto de princípios e teorias que servem de modelo ou quadro orientador às pesquisas produzi das na sua área ${ }^{15}$. Essas concepções não ocupam posições contraditórias, mas refletem realidades diferentes; são transitórias porque fazem parte de um processo que se (re)constrói a cada momento de modo diferente, dependendo das regras do campo científico. Portanto, éfundamental situar que esse trabalho aproxima dois campos científicos em um espaço de interface entre duas ciências, em uma realidade contemporânea dinâmica.

E éde uma forma semiótica, considerando as regras vigentes dos campos no sentido de Bour- 
dieu³, com os mínimos detalhes, que podemos observar como essas categorias vão produzir, perceber e interpretar os sentidos e significados nas práticas de alimentação. Segundo Geertz ${ }^{16}$, os homens: el es também, até o último deles, são artefatos culturais, e é assim que a comida se constitui como uma propriedade humana fundadora da identidade tanto individual como coletiva. Ela sesitua dentro deum jogo dedistinção ealteridade no qual os homens registram seu pertencimento a uma cultura ou a um grupo qualquer seja pela afirmação de sua especificidade alimentar ou pela diferença em relação ao outro ${ }^{6}$.

A ideia de alimento como produto de um "ato natural", fruto de necessidade biológica do homem, está inserida na construção racional da modernidade, em quea idei $a^{17}$ denatureza desdivinizada é dissociada ao mesmo tempo do sagrado e do humano, e é colocada na objetividade, uma objetividade "material". Esse estado "natural", verificável evisível, éconsiderado inato em todos os homens e se contrapõe à razão, àquilo que se deduz pelo pensamento, ou raciocínio, eépor ele pensado e planejado. 0 "natural', assim, se "naturaliza" por objetivação, tornando-se inquestionável, algo que pode ser observado e verificado pelas "leis da natureza", efica imobilizado na concepção de uma verdade universal que assume 0 sentido de uniforme, nos termos em que discute Jullien ${ }^{18}$. Segundo $\mathrm{Luz}^{17}$, a racionalidade moderna torna a natureza "objeto", e a razão, instrumentada pela observação repetida, repertoriada, tecnificada, [...] "sujeito" do conhecimento.

A ciência da Nutrição, que se constituiu na modernidadecientífica, desenvolveu suas concepções nesta ten dência da racionalidade, buscando responder às questões objetivas sobre o que devemos comer para ter uma vida com menores riscos de adoecimento. No entanto, enfrenta novos desafios quando elabora intervenções que demandam um controle dos efeitos de um novo modo de comer que vem se construindo na sociedade contemporânea. A concepção de alimento, no sentido de algo comestível que contém os nutrientesnecessários à vida, mantém correspondência com um domínio ou campo disciplinar expresso institucionalmenteatravés de vasto conjunto de grupos de pesquisa, dezenas de programas de formação de pesquisadores e milhares de publicações no Brasil e na literatura internacional. Enfim, seguindo os pensamentos ${ }^{2-19}$ acerca da constituição de campos científicos, esse objeto "alimento" e as forças sociais que o conceberam lograram um vasto domínio solidamente institucionalizado.
No entanto, a comida pode assumir diferentes significados, que dão sentido às ações sociais, no sentido weberiano ${ }^{20}$ de ação para 0 outro, que se deslocam de um contexto cultural para outro. 0 significado é uma idéia convencional e arbitrária atribuída ao significante (som) e ao signo (fixação do som/símbolo do som). 0 significado é, portanto, uma atribuição sócio-cultural mais ou menos consciente (racionalizada), incluindo diferentes graus de discursividade ${ }^{21}$.

A questão apresentada neste trabalho não envolve somente "o que se ingere", mas "como se come 0 quê", o que confere às experiências vividas menos "objetividade" do que se espera na tradição dos inquéritos nutricionais ${ }^{22}$, levando a questão para a dimensão da subjetividade.

A comida representou uma riqueza para o homem eécapaz de expressar, ao longo da sua história, a constituição das estruturas sociais desde 0 momento em que se diferenciou dos outros animais, ao prepará-la e socializá-la, e dessa forma dividindo o trabalho para consegui-la. Engel $s^{23}$, em sua pesquisa sobre a origem da família na construção da organização social, nos fala sobre o processo de formação de estruturas, em que a primeira divisão do trabalho éa que sefez entreo homem ea mulher para a procriação do filho. 0 desenvolvimento detécnicas para cultivo do solo, a partilha da produção e a divisão do trabalho estão na base da formação dos núcleos familiares, que desde 0 começo está relacionada com os serviços da agricultura. As questões dessa divisão (que são sociais) vão desde como conseguir o alimento, plantio ou extrativismo, caça ou criação, até de quem vai se ocupar do plantio e do preparo, papéis masculinos e femininos que reproduzimos, de certa maneira, até hoje nos cuidados domésticos com alimentação e educação nos núcleos familiares.

Nos modos tribais coletivos de alimentação, já tínhamos determinado al guns gêneros alimentícios que seriam comestíveis e já se estabelecia uma escala de valores entre bons, ruins, sagrados. 0 processo de organização das tribos segue uma ordem de distribuição da comida, estabelecendo como os alimentos seriam consumidos, qual seria cru e qual seria cozido, em que momento haveríamos de comêlos e em que situação: comida de festa ou do cotidiano. Vale lembrar aqui a grande contribuição dos trabalhos antropológicos de Lévi-Strauss ${ }^{24}$ em sua obra sobre indígenas do Centro-O este brasileiro, em que 0 autor discute $o$ cultural na transformação do alimento cru em cozido.

Se a comida era ela mesma uma riqueza, com o passar do tempo foram sendo utilizados no- 
vos materiais e novas técnicas que permitiram acumular excedentes de produção alimentícia, e ela pode ser trocada, assumindo valores e preços, expressando, assim, um processo de transformação social do alimento. Engel ${ }^{23}$ discuteesse processo de constituição das relações comerciais e mostra como a transformação da comida em mercadoria representou também a transformação do homem, pois também o homem podia servir de mercadoria, [...] a força de trabalho do homem podia chegar a ser objeto de troca e consumo, desde que o homem se transformasse em escravo.

\section{A Alimentação}

Se a comida assume significados, o que é uma ideia convencional e arbitrária, 0 alimentar-se assume sentidos ${ }^{21}$ que dizem respeito à significação no contexto de um universo imagi nário e simbólico, não necessariamente racional [mas] capaz de produzir identidades individuais e coletivas, relações sociais evínculos que ultrapassam a lógica consciente do discurso.

A vida social se organiza em conjunto com a alimentação. H ernandez eArnai $z^{25}$ citam autores que trabal ham a alimentação como expressão de um modo de vida e como forma de comunicação, além de indicar usos em que os significados estão organizados sistematicamente.

A culinária ou "cozinha" é expressão da vida social, um modo de se reunir, um modo de dividir a comida, um modo de dividir os trabalhose assim por diante, que segue regras instituídas na sociedade. Os princípios de condimentação, por exemplo, com seu uso e sabor, identificam um prato como próprio de uma cultura.

Uma cozinha, além dos ingredientes, denota princípios de condimentação, procedimentos culinários, conjunto de regras de uso, de prática, de representação simbólica e de valores sociais, morais, religiososehigiênicos ou sanitários ${ }^{15}$. Perceber as "regras" que permeiam o modo de preparar e comer os alimentos é perceber que não há uma natureza constante, a priori, mas um jogo de interesses e de forças que se reconstroem a todo momento, o que nos remete a Bourdieu ${ }^{3}$ quando nos diz que o campo é um jogo no qual as regras do jogo estão elas próprias postas em jogo. 0 universo da alimentação "é um campo" que sofre pressões do campo econômico e político e, assim, está sujeito a imposições comerciais através da mídia e de determinações do Estado, entre outros.

As ações realizadas no "estar junto" (re) produzem uma estrutura social ${ }^{26} \mathrm{em}$ que
Cada agente, quer ele saiba ou não, quer ele queira ou não, é produtor e reprodutor de sentido objetivo: porque suas ações são o produto de um modus operandi do qual ele não é o produtor e do qual não tem o domínio consciente.

Uma refeição, como almoço ou jantar, é uma situação estruturada que se diferencia de um lanche ligeiro, que não segue a mesma ordem normativa como, por exemplo: entrada, prato principal, guarnições, bebidas, sobremesa etc. Cada segmento dessa ordem pode expressar as condições sociais edar sentido às práticas de alimentação refletindo ou explicando essas condições, quer os agentes dessa prática queiram, quer não.

A proximar as áreas das Ciências Sociais e da Saúde é uma forma de compartilhar conhecimento e, no jogo cotidiano no campo científico, poder unir forças e interesses. Um estudo de $\mathrm{Ca}$ nesqui ${ }^{27}$ sobre a prática al imentar defamílias trabal hadoras urbanas discute o consumo da carne em dois momentos diferentes da década de 70; une forças quando aproxima dois campos científicos. Segundo a autora, a construção de significado para a carne em um grupo de trabal hadores segue uma trajetória social de transformação em que a carne representa gêneros "menos necessários", ora comparecendo entre os de "luxo", na primeira pesquisa, por força das barreiras do acesso eda raridadedeseu consumo, descolando-se, na segunda pesquisa, das aspirações para o consumo efetivo, simbolizando a prosperidade alimentar, 0 maior poder de compra e o cumprimento a contento dos deveres paternos ${ }^{27}$.

A carne para essas famílias não tem o mesmo significado nos dois momentos e traz sentidos diferentes à prática alimentar. Comer arroz efeijão com carne está intimamenteligado às condições de vida e de trabalho, e tanto assume um sentido de sustentação para o trabalho, vigor, sustança, como de prestígio e sensação de dever cumprido.

Hernandez e Arnaiz ${ }^{25}$ falam sobre um realce nas proibições de alimentos de origem animal em relação aos de origem vegetal no decorrer da história, sugerindo que a fonte animal tem sido socialmente considerada como melhor em termos de status, a ponto de em algum momento se medir a prosperidade de um período pelo consumo per capita de carne. Essa valorização do alimentar-se de carne, na perspectiva das Ciências Sociais, pode ser um el emento de construção do gosto - considerado por muitos uma competência individual da ordem do singular - que representa necessidade de construir e se apropriar das experiências vividas coletivamente, embora 
nem sempre isso aconteça de uma forma consciente. A sensação do gosto traduz uma cultura incorporada, tem um caráter coletivo que não se opõe ao individual, que o complementa, produzindo ou reproduzindo relações entre o corpo e 0 alimento. Segundo Canesqui e Garcia ${ }^{9}$, o gosto e o paladar, em vez de se naturalizarem, são cultivados no emaranhado da história, da economia, da política e da própria cultura.

0 alimentar-sevai além de uma questão fisiológica denecessidade denutrientese constrói costumes, acompanha ritos de passagem, liberta os espíritos esela relações entreo indivíduo ea sociedade. Segundo Gallian ${ }^{28}$, não émera coincidência que Alguns dos acontecimentos e idéias mais importantes e marcantes da história da civilização ocidental estão inseridos em contextos de refeições ou banquetes. Esse autor cita aúltima ceia de Jesus Cristo, que representa um marco histórico na espiritualidade e que é rememorada em cerimônia eucarística até hoje como um momento sagrado. Cita também o banquete de Platão, que representa um marco histórico no pensamento com um debate filosófico sobre o amor. Bakhtin ${ }^{29}$ reflete sobre o espírito renascentista, no banquete de Rabelais, através do personagem Gordo-Guilherme, um espírito que revela verdade na imanência do mundo: 0 encontro do homem com o mundo que se opera na grande boca [...] é um dos assuntos mais antigos emarcantes do pensamento humano. Para Gallian ${ }^{28}$, o banquete é sempre uma escola dos sentidos: Antes de comer é preciso apreciar com os olhos, sentir o aroma, a textura e saborear, discernindo bem as características, os "acidentes" dos diversos ingredientes e condimentos. Toda verdadeira "refeição", seja simples seja mais sofisticada, "significa, comunica e evoca algo" que é preciso decifrar e identificar.

Distintamente do que se passa com o domínio do alimento, a alimentação vem se constituindo de modo difuso em variados campos científicos, esparsos, por meio de projetos isolados ou linhas de pesquisa que compõem programas de pós-graduação. Não mais que algumas poucas dezenas grupos de pesquisa ${ }^{2}$ dirigem seus esforços acadêmicos para esse foco; representação da hegemonia de um certo ol har fragmentador, especialista, disciplinar, que ao tentar descrever e explicar a vida converte-a em atomização de conhecimentos esparsos e desintegrados. Em outras palavras, um paradoxo do mundo científico em que 0 alimento se faz afastado da alimentação, da comida, da cozinha, da culinária.

M as é interessante a presença, ainda que pe quena, de abordagens que partem das $\mathrm{H}$ umanida- des para o alimento - tal como apresentado pelos cientistas da composição química ou das maisinovadoras tecnologias de produção - em busca de seus significados e dos sentidos que Ihes são conferidos, colocando em debatetemas como o medo do desconhecido (transgênicos, irradiados...) esuas implicações sobre o consumo, como a busca por novos modos de se alimentar ou tentativas de recuperação de antigos padrões alimentares e 0 investimento em movimentos de desconfiança ereação ao que vai sendo apresentado como científico e, por isso, bom. Da mesma forma e na outra mão do trânsito de saberes, há estudos ${ }^{30,31}$ que partem de lugares como as Ciências dos Alimentos e buscam, nas Ciências Sociais e Humanas, suporte conceitual e metodológico para abordagens sobre representações dos alimentos gerados em seu berço científico deorigem.

\section{A Nutrição}

A Nutrição, como ciência, se consolida quando o ato desealimentar setorna objeto deintervenção, de model ação e de produção de uma forma específica de racionalismo voltado para a ingestão do alimento. Segundo $\mathrm{Luz}^{17}$, a racionalidade moderna funciona como estrutura epistemológica de explicação e ordenação dos seres e do mundo, e como princípio moral das relações entre os homens e as coisas, e dos homens entre si [...]. U m dos produtos dessas formas de pensar o corpo foi o surgimento das ciências da nutrição no século XIX, [...] que marca uma ruptura no conceito de se alimentar.

A ciência da $\mathrm{N}$ utrição ${ }^{31}$ condiz com o enfoque da "norma", da dieta regulada [...] por ser um termo de caráter técnico, [...] que recupera representações com conteúdo envernizado tecnicamente. N esse contexto da modernidade, a disseminação do biopoder nas instituições sociais, segundo Foucault ${ }^{32}$, torna o indivíduo cada vez mais responsável pelos riscos produzidos no ambiente e promove a incorporação de preocupações e de controle social. Assim, Garcia ${ }^{33}$ diz quea idéia de que o que é gostoso comer pode ser perigoso para a saúde [...] impõe um novo gênero de vida regrada, o que se associa à dicotomia que discute Douglas ${ }^{34}$, entre sujidade e limpeza, que está ligada à ordem e desordem. Quanto mais o conhecimento de práticas de higienefoi avançando, no sentido da especificação e tecnologização, mais a valorização dessas práticas foi se incorporando "naturalmente" na modernidade, transformando nossa alimentação em razão dessa valorização. 0 que foi se construindo com a ciência da 
Nutrição correspondeu a uma forma moderna deordenamento da alimentação, uma forma que tem como objetivo desvendar uma espécie de "grande quebra-cabeça cósmico"13 que tem agora um ordenador: a ciência.

Numa perspectiva mecanicista presente na concepção moderna da N utrição, 0 alimento, assim como o corpo, é fragmentado para ser observado com exatidão erepresentado por elementos mensuráveis e abstratos. Os nutrientes podem instrumentalizar cálculos de probabilidades diversas. N esse caso, a construção de sentidos envolvendo a Nutrição como saber segue, conscienteou inconscientemente, outra lógicaque sedistancia da das Ciências Sociais e seaproxima da Biologia e da M edicina modernas. A N utrição é, de fato, parte do campo biomédico a partir da segunda metade do século XIX eseconstitui como estratégia discursiva da saúde, ligada à Epidemiologia no século XX.

Assim, se dieta representava um regimede vida na teoria hipocrática dos humores, precursora das "receitas" médicas²2 dessa época, na N utrição da modernidade dieta representa uma prescrição ou orientação que, seguindo as recomendações deconsumo diário denutrientes, deve estabelecer as quantidades de alimentos e os horários em que estes devem ser consumidos. N uma sociedadeem que a ordem alimentar segue a disseminação do biopoder, "fazer dieta" carrega consigo o sentido de restrição de um regime de vida, primando por práticas voltadas para o controle e a segurança, como modo ou tentativa de evitar a doença, de afastar os riscos à saúde.

Se $o$ alimento vem majoritariamente tratado cientificamente como al go cindido da Alimentação, o mesmo se passa com a pesquisa em Nutrição. Embora se apresentando com as vestes de uma formação discursiva que valoriza a cultura do indivíduo ou da população, a práxis correspondente a essefalar não vai além do equivalente a duas ou três linhas que compõem textos de dezenas e dezenas de páginas de cunho biomédico. I sso tem um peso enorme, dado quea Nutrição ${ }^{2}$ tem, como base institucional de produção de conhecimento, dimensões que ficam pouco atrás do campo das Ciências dos Alimentos.

Ao mesmo tempo, é possível observar mudanças recentes nos interesses teóricos de pesquisa e de práticas no campo da N utrição. Constata-se o crescente aumento global da obesidade e dos conhecimentos sobre relações de doenças crônicas e alimentação associado à questão da baixa adesão às dietas e orientações nutricionais. A dificuldade em dar respostas a essas questões por meio do universo dos nutrientes ou dos fatores isolados determinantes de processos patológicos, bem como a crescente percepção dos limites dos métodos epidemiológicos para dar conta de questões relativas à complexidade dos comportamentos e práticas al imentares, juntamente com a desconfiança da sociedade em geral da alimentação industrializada, da busca de novas tecnologias alimentares ao lado de clamores por uma economia sustentável, capaz de não danificar o planeta em termos ecológicos, enfim, todas estas questões têm gerado cada vez mais interesse pela alimentação em seu sentido ampliado, por assim dizer, socioantropológico. Nesse cenário, emergem movimentos no interior da N utrição, e da Saúde em geral, que a aproximam das Ciências Sociais, seguindo uma tendênciatida como estratégica, rumo à construção de cooperação entre distintos saberes.

\section{Consideraçõesfinais}

Podemos observar atualmente, apesar da tendência à especialização disciplinar, quase paradoxalmente, um movimento de aproximação entre os diversos campos disciplinares na busca pela integralidade e pela interdisciplinaridade, nos termos queapresentamos na introdução destetrabalho. A cooperação entre distintos e especializados campos de saber científico tem sido fundamental no enfrentamento de temas complexos como os da "Alimentação", em que os alimentos assumem significados e dão sentido às nossas ações cotidianas.

As transformações que vêm ocorrendo na realidade, na alimentação, desejadas ou indesejadas, contam com um hibridismo de padrões que representa tanto uma mudança de regras, de preferências alimentares, como de novas combinações associadas a novas técnicas de preparo capazes de identificar ede dar sentido de pertencimento aos comensais. N esse sentido, o alimento não serve somente para comer; serve para pensar, como assinala Lévi-Strauss ${ }^{24}$, mas também para comunicar. A construção de um produto com uma ideia de "novo" se tornou uma necessidade deconsumo. A escolhaalimentar não diz respeito somente a uma questão racional, mas à construção de novas sensibilidades, transformações e permanências de significados nas práticas de alimentação. Os sentidos estão no campo de pesquisa, na realidade objetiva (em nível simbólico), e os conceitos, em nossas possibilidades de discutir os elementos percebidos no campo. A construção dos sentidos e significados na prática da 
pesquisa em alimentação demanda uma articulação entreos elementos percebidos na vivência das relações sociais e as possibilidades de pensá-los, iluminados pelas teorias e pela conceituação.

Nosso desafio teórico é construir um espaço comum para que o compartilhar das categorias analíticas se torne, tanto em termos de representações como derelações sociais, uma prática cotidiana na pesquisa científica. Sabemos que há disputas e controvérsias em torno das regras dos campos científicos equeos agentes podem resistir, seopondo, ou aceitar eaté incentivar novas práticas.

As categorias discutidas neste artigo, aplicadas à pesquisa científica, podem assumir significados e sentidos diferentes, ora fortes, ora frágeis, dependendo seestão no campo da Saúde ou das Humanidades. No entanto, tornam-se instrumentos analíticos importantes no campo das ciências em geral, como modo de reflexão sobre 0 viver. 0 ponto central é que através da conceituação podemos desnaturalizar saberes científicos aprisionados em uma área restrita e inserilos em um espaço compartilhado de pesquisa, academicamente legitimado, e desse modo sermos menos dependentes de um modelo uniforme de saber e mais livres para pensar nossas questões na vida.

\section{Colaboradores}

M CVS Carvalho trabal hou na concepção, no delineamento e redação final do artigo; MT Luz, na concepção e revisão crítica da redação do artigo; SD Prado, na revisão crítica do artigo e redação final. 


\section{Referências}

1. Prado SD. A pesquisa sobre Alimentos, Alimentação e Nutrição no Brasil: reflexões sobre a produção de conhecimento e saberes [projeto de pesquisa]. Rio de Janeiro: Instituto de Nutrição, U erj; 2005.

2. Prado SD, Luz MT, Carvalho MCS, Bosi MLM , Camargo Jr KR, Silva JK, Ornelas TFS, Oliveira PF. Ciência e Tecnologia de Alimentos, Nutrição e Alimentação como campos científicos no Brasil [relatório de pesquisa]. Rio de Janeiro: Instituto de Nutrição, U erj; 2009.

3. Bourdieu P. O poder simbólico. Lisboa: Difel; 1989.

4. Silva AS. A ruptura com o senso comum nas ciências sociais. In: Silva AS, Pinto JM . M etodologia das Ciências Sociais. Porto: Afrontamento; 2003. p. 29-53.

5. Carvalho MCVS, Luz MT. Práticas de saúde, sentidos e significados construídos: instrumentos teóricos para sua interpretação. Interface - Comunic, Saude, Educ 2009; 13(29):313-326.

6. Santos LAS. 0 corpo, o comer e a comida: um estudo sobre as práticas corporais e alimentares no mundo contemporâneo. Salvador: EdUFBA; 2008.

7. Luz MT. Complexidade no campo da Saúde Coletiva: multidisciplinaridade, interdisciplinaridade e transdisciplinaridade de saberes e de práticas: análise sócio-histórica de uma trajetória paradigmática. Saúde Sociedade 2009; 18(2):304-311.

8. Czresnia D. Epidemiology, Social and Human Sciences and integration of sciences. Rev Saude Publ 2008; 42(6):1112-1117.

9. Canesqui AM, Garcia RWD. Ciências Sociais e Humanas nos cursos de Nutrição. In: Canesqui AM, Garcia RWD, organizadoras. Antropologia e Nutrição: um diálogo possível. Rio de Janeiro: Editora Fiocruz; 2005. p. 255-274.

10. Canesqui AM, Garcia RWD. Uma introdução à re flexão sobre a abordagem sociocultural da alimentação. In: Canesqui AM, Garcia RWD, organizadoras. Antropologia e Nutrição: um diálogo possível. Rio de Janeiro: Editora Fiocruz; 2005. p. 9-19.

11. Almeida JF, Pinto JM. Da teoria à investigação empírica: problemas metodológicos gerais. In: Silva AS, Pinto JM. M etodologia das Ciências Sociais. Portugal: Afrontamento; 2003. p. 55-78.

12. Arnaiz MG. Em direção a uma nova ordem alimentar? In: Canesqui AM, Garcia RWD, organizadoras. Antropologia e Nutrição: um diálogo possível. Rio de Janeiro: Editora Fiocruz; 2005. p. 147-164.

13. Bourdieu P. Os usos sociais da ciência: por uma sociologia do campo científico. São Paulo: Ed. Unesp; 2003.

14. Bourdieu P. Sobre a televisão, a influência do jornalismo e os jogos olímpicos. Rio de Janeiro: Jorge Zahar; 1997.

15. Montanari M. Comida como cultura. São Paulo: Editora Senac; 2008.

16. Geertz C. A interpretação das culturas. Rio de Janeiro: Livros Técnicos e Científicos; 1989.

17. Luz MT. Natural, racional, social: razão médica e racionalidade científica moderna. Rio de Janeiro: Campus; 1989.

18. Jullien F. Diálogo entre as culturas, do universal ao multiculturalismo. Rio de Janeiro: Jorge Zahar; 2009.
19. Stengers I. Da racionalidade científica (capturas, eventos, interesses). In: Stengers I. Quem tem medo da ciência: ciências e poderes. São Paulo: Siciliano; 1990. p. 77-109.

20. Weber M. Ação social e relação social. In: Martins JS, Foracchi M, organizadores. Sociologia e sociedade: leituras de introdução à sociologia. Rio de Janeiro: Livros Técnicos e Científicos; 1977. p. 139-144.

21. Mattos RS, Luz MT. Sobrevivendo ao estigma da gordura: um estudo socioantropológico sobre obesidade. Physis 2009; 19(2):489-507.

22. Garcia RWD. Representações sobre consumo alimentar e suas implicações em inquéritos alimentares: estudo qualitativo em sujeitos submetidos à prescrição dietética. Rev Nutr 2004; 17(1):15-28.

23. Engels F. A origem da família, da propriedade privada e do Estado. Rio de Janeiro: Vitória; 1964.

24. Lévi-Strauss C. 0 cru e o cozido. São Paulo: Cosac \& Naify; 2004.

25. Hernandez JC, Arnaiz M G. Alimentación y vultura: perspectivas antropológicas. Barcelona: Ariel; 2005.

26. Ortiz R. à procura de uma sociologia da prática. In: Ortiz R, organizador. Pierre Bourdieu. São PauIo: Ática; 1994.

27. Canesqui AM. Mudanças e permanências da prática alimentar cotidiana de famílias de trabalhadores. In: Canesqui AM, Garcia RWD, organizadoras. Antropologia e Nutrição: um diálogo possível. Rio de Janeiro: Editora Fiocruz; 2005. p. 167-201.

28. Gallian DM C. A desumanização do comer. Estudos Avançados 2007; 21(60):179-184.

29. Bakhtin M A. A cultura popular na Idade M édia e no Renascimento: 0 contexto de François Rabelais. São Paulo: Hucitec; 1987.

30. M enache R. Frankenfoods e representações sociais: percepções contemporâneas sobre biotecnologia, natureza e alimentação. Revista Theomai [periódico na Internet], 2003, número especial [acessado 2009 maio 20]. Disponível em: http://revistatheomai. unq. edu.ar/numespecial2003/artmenasche\%20numesp 2003.htm

31. M enache R. Alimentos transgênicos: no meu prato não? Democracia Viva 2005; 26:8-15.

32. Foucault M. Microfísica do poder. Rio de Janeiro: Graal; 1982.

33. Garcia RWD. Alimentação e saúde nas representações e práticas alimentares do comensal urbano. In: Canesqui AM, Garcia RWD, organizadoras. Antropologia e Nutrição: um diálogo possível. Rio de Janeiro: Editora Fiocruz, 2005. p. 211-225.

34. Douglas M. Pureza e perigo. São Paulo: Perspectiva; 1976.

Artigo apresentado em 10/02/2010

Aprovado em 20/05/2010

Versão final apresentada em 12/07/2010 